\title{
Oral Health and Public Health Systems in Europe
}

\author{
Ambarkova Vesna* \\ Department of Paediatric and Preventive Dentistry, Faculty of Dental Medicine, Republic of Macedonia
}

*Corresponding author: Ambarkova Vesna, Department of Paediatric and Preventive

Dentistry, Faculty of Dental Medicine, Skopje, Republic of Macedonia.

Received Date: November 02, 2018

Published Date: November 20, 2018

\section{Opinion}

Oral health care in Europe is provided by a diverse range of services. In the Nordic countries children are eligible for public dental services, whereas adults and the majority of older people receive health care from private dental practitioners with national and local co-payment systems [1].

In southern Europe, private dental practitioners dominate, and third-party payment is based on private insurance or costs are paid by employers [2]. While in eastern Europe and central Asia, oral health services are based on a blend of public and private systems $[3,4]$.

The current situation is like that the use of oral health services varies significantly by country. In all countries the poor and disadvantaged population group are underserved $[5,6]$. Price $J$ et all in a retrospective observational study concluded that the socioeconomic status (SES) gradients indicate inequity in the orthodontic outcomes, with children from disadvantaged communities having poorer outcomes compared to their more affluent peers [7]. Over a third of cases had unreported Index of Orthodontic Treatment Need (IOTN) outcome scores, which highlights the need to improve the outcome monitoring systems. While $7.6 \%$ of treatments ending in discontinuation $(£ 2.3 \mathrm{~m})$ and $5.2 \%$ ending with residual need $(£ 1.6 \mathrm{~m})$, showing Substantial inefficiencies evidence of the National Health Service in England [7].

Although oral diseases are preventable, most oral health services in Europe are largely treatment oriented. Health systems have to be reoriented from a conventional model of restorative dentistry towards a preventive model of care and integrated into health systems at all levels [1].

Rychlik $\mathrm{R}$ et al. assumed that large cost savings were possible, because the regular consumption of sugar-free gum (SFG) significantly reduces the relative risk of caries and therefore, improves dental health, which reduces expenditures on dental treatments. Good dental hygiene like tooth brushing cannot be replaced by used of sugar-free gum but can have a significant impact on dental health, which can lead to increased cost savings for health care systems worldwide. Clinical significance of Rychlik R et al. study is that an increased consumption of sugar-free gum may not only lead to improved dental health but significant cost savings in expenditures for dental treatment worldwide [8].

\section{Acknowledgement}

None.

\section{Conflict of Interest}

Authors to declare no conflict of interest.

\section{References}

1. Fisher J, Selikowitz HS, Mathur M, Varenne B (2018) Strengthening oral health for universal health coverage. Lancet 392(10151): 899-901.

2. Nikolovska J (2013) Oral health care provision systems in the black sea countries part 14: The Republic of Macedonia. Oral Health Dent Manag 12(2): 61-64.

3. Rao KD, Paina L, Ingabire MG, Shroff ZC (2018) Contracting non-state providers for universal health coverage: learnings from Africa, Asia, and Eastern Europe. Int J Equity Health 17(1): 127.

4. Karanikolos M, Adany R, McKee M (2017) The epidemiological transition in Eastern and Western Europe: a historic natural experiment. Eur J Public Health 27(suppl_4): 4-8.

5. Phantumvanit P, Makino Y, Ogawa H, Rugg-Gunn A, Moynihan P, et al. (2018) WHO Global Consultation on Public Health Intervention against Early Childhood Caries. Community Dent Oral Epidemiol 46(3): 280287.

6. Mangrio E, Sjögren Forss K (2017) Refugees' experiences of healthcare in the host country: a scoping review. BMC Health Serv Res 17(1): 814.

7. Price J, Whittaker W, Birch S, Brocklehurst P, Tickle M (2017) Socioeconomic disparities in orthodontic treatment outcomes and expenditure on orthodontics in England's state-funded National Health Service: a retrospective observational study. BMC Oral Health. 17(1): 123.

8. Rychlik R, Kreimendahl F, Blaich C, Calache H, Garcia-Godoy F, et al. (2017) A global approach to assess the economic benefits of increased consumption of sugar-free chewing gum. Am J Dent 30(2): 77-83. 